BMJ Paediatrics Open

\title{
Exploring spatiotemporal distribution of under-five mortality in Ethiopia: further analysis of Ethiopian Demographic and Health Surveys 2000, 2005, 2011 and 2016
}

Alemneh Mekuriaw Liyew (D) ,' Ayenew Kassie, ${ }^{2}$ Achamyeleh Birhanu Teshale, ${ }^{1}$ Adugnaw Zeleke Alem, ${ }^{1}$ Yigizie Yeshaw, ${ }^{1,3}$ Getayeneh Antehunegn Tesema ${ }^{1}$

\section{ABSTRACT}

Objective The aim of this study was to explore spatiotemporal distribution of under-five mortality in Ethiopia using data from four $(2000,2005,2011$ and 2016) consecutive demographic and health surveys.

Methods A total of 41498 children were included from four consecutive Ethiopian Demographic and Health Surveys. The geospatial analysis was conducted by using ArcGIS V.10.7 and saTScan V.9.6. Thus, spatial autocorrelation, hotspot analysis, spatial interpolation and spatial scan statistics were carried out for each survey separately to show the temporal pattern of geographically risk areas of under-five mortality in Ethiopia. Finally, the most under-five mortality rate (U5MR) risk areas in each survey period were mapped.

Results Under-five mortality was spatially clustered in Ethiopia (Moran's Index: 0.046-0.096, $p<0.01$ ). The Benishangul-Gumuz region was consistently at a higher risk in the last two decades. Additional hotspot areas were detected at Afar and Amhara (in 2000, 2005, 2016), at Gambala (in 2011) and the South Nation Nationality and People's (SNNP) Region (in 2016). Moreover, 160 primary clusters were identified. Of these, 85 clusters $($ log-likelihood ratio $(L L R)=13.10, p<0.01)$ were from Benishangul-Gumuz and Amhara regions (in 2000); 67 clusters ( $L L R=12.93, p<0.01)$ were from Afar and Amhara regions (in 2005); 4 clusters ( $L L R=10.54, p<0.01$ ) were from Benishangul-Gumuz region (in 2011); and another 4 clusters (LLR $=11.85, p<0.01$ ) were from Afar region (in 2016).

Conclusion High-risk areas were detected mainly in the Benishangul-Gumuz and Afar regions. As a result, designing under-five population targeted intervention programmes in those high-risk geographical regions was vital to reduce under-five mortality in Ethiopia. commercial re-use. See rights and permissions. Published by BMJ.

For numbered affiliations see end of article.

Correspondence to Alemneh Mekuriaw Liyew; alemnehmekuriawliyew@gmail. com

\section{INTRODUCTION}

Although there has been a substantial reduction in the under-five mortality rate (U5MR), in 2018, more than 15000 children died before celebrating their fifth birthday. Globally, the U5MR is 39 deaths per 1000 live births but there is a stark difference between

\section{What is known about the subject?}

The under-five mortality was a major public health problem in Ethiopia. In previous studies, the prevalence of under-five mortality and socioeconomic and sociodemographic factors that affect under-five mortality were assessed.

\section{What this study adds?}

> The under-five mortality had spatial dependency over the last 20 years in Ethiopia. The hotspot (high risk) areas were mainly detected in BenishagulGumuz across four surveys. Besides, Amhara, Afar, Gambela and South Nation Nationality and People's Region were at higher risk of under-five mortality.

developing and advanced countries. The sub-Saharan Africa and central and southern Asia accounted for more than $80 \%$ of the 5.3 million under-five deaths in 2018. Current evidence shows that Saharan countries have a very high U5MR (ie, 78 deaths per 1000 live births). This is 1 child in 13 dies after surviving the first month before his or her fifth birthday. This is 16 times higher than the average ratio of 1 in 199 in high-income countries. ${ }^{12}$ Ethiopia is among the five countries which account half of all global under-five deaths in $2018,{ }^{2}$ with the U5MR of 67 deaths per 1000 live births. ${ }^{3}$ Despite progressive and consistent health intervention, U5MR shows the highest trend in Ethiopia. ${ }^{4-6}$

In the Sustainable Development Goal 3 (SDG 3), the targets for neonatal mortality and U5MR are specified to be less than 12/1000 live births and 25/1000 live births, respectively. ${ }^{7}$ Furthermore, the target was extended to the elimination of preventable child deaths 


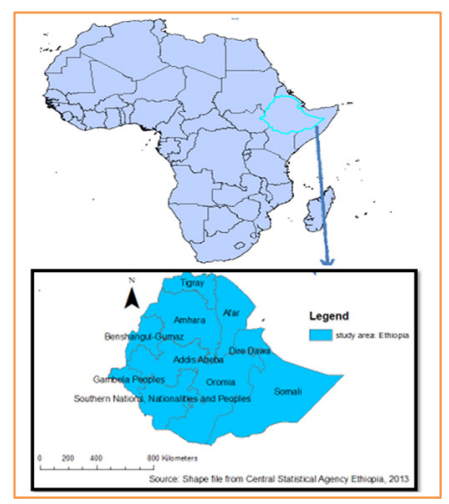

Figure 1 Map of Ethiopia where the four surveys were conducted. (Source: Shapefile from Central Statistical Agency, Ethiopia, 2013.)

between birth and age 5 by 2030. Thus, the SDG framework requires giving attention to subgroups that may be missed from traditional measurement systems. ${ }^{89}$

Previously, different studies were conducted on underfive mortality in Ethiopia. ${ }^{10-20}$ However, these studies mainly focused on assessing the factors associated with under-5 mortality without statistically investigating its spatiotemporal distribution. Thus, there is a literature gap on the spatial pattern and spatiotemporal distribution of under-five mortality across regions in Ethiopia.

Spatiotemporal distribution analysis is key for understanding the geographical risk areas of under-five mortality by showing the specific location of the risk areas over time. The basic assumption of spatial analysis goes to Tobler's first law which focuses on the notion that near things are more related than distant ones. ${ }^{21}$ Toblers first law states that "everything is related to everything else, but near things are more related than distant things". This concept is considered as the core of spatial autocorrelation statistics (for analysing correlation relative to distance or connectivity relationships). Moreover, it is central to every spatial analytical techniques as well as analytical conceptions of geographic space. ${ }^{22}$

Consequently, the evidence that under-5 mortality might be concentrated in an area over time is vital to assess the public health impact of maternal and child health intervention programmes applied so far. Besides, it will provide input for future health planning by identifying high priority areas. Therefore, the objective of this study was to assess the spatiotemporal distribution of under-5 mortality and whether the distribution has changed significantly overtime in Ethiopia by using data from four consecutive large national surveys.

\section{METHODS}

\section{Patient and public involvement}

This study used a publicly available dataset (Ethiopian Demographic and Health Survey (EDHS) 2016); therefore, there were no patients or members of the public directly involved.

\section{Study design and setting}

The data from four consecutive EDHS (2000, 2005, 2011 and 2016) were used for this study. The surveys were conducted at 5-year interval cross sectionally at the national level. Ethiopia is an East African country that is located at the horn of Africa (figure 1). The country is administratively subdivided into nine regional states such as Afar, Amhara, South Nation Nationality and People's (SNNP) Region, Benishangul-Gumuz, Gambela, Harari, Oromia, Somalia, Tigray and two city administrations (Addis Ababa and Dire Dawa).

\section{Data source and sampling}

Each Demographic and Health Survey adopted a twostage stratified sampling technique based on the population and housing census sampling frame designed to collect data at the national, zonal, state and rural-urban levels during previous censuses. ${ }^{3}$ In the first stage, clusters or enumeration areas (EAs) were selected with probability proportional to population size. A total of 540,540 , 624 and 645 EAs (clusters) were selected in 2000, 2005, 2011 and 2016, respectively. The second stage involved the systematic sampling of households in each selected cluster. Thus, total samples of 14642, 14645, 17817 and 18008 households were selected in 2000, 2005, 2011 and 2016 surveys, respectively. In all surveys, a reproductive age (15-49) women were interviewed about the survival status of their children. As a result, data on the sex, month and year of birth, number of births, current age (if the child is alive) and age at death (if the child is dead) were collected. For the current study, a total of 41498 children were extracted from four surveys and included in the analysis (table 1). Additional information about the sample selection and data structure can be obtained from each EDHS reports available on https://

Table 1 The total number of study participants and the year of the survey

\begin{tabular}{lrrrrr}
\hline & \multicolumn{3}{l}{ Year of survey } & & \\
\cline { 2 - 5 } Regions & $\mathbf{2 0 0 0}$ & $\mathbf{2 0 0 5}$ & $\mathbf{2 0 1 1}$ & $\mathbf{2 0 1 6}$ & Total \\
\hline Tigray & 1248 & 958 & 986 & 990 & 4182 \\
Afar & 715 & 574 & 942 & 1074 & 3305 \\
\hline Amhara & 1770 & 1437 & 1035 & 938 & 5180 \\
\hline Oromia & 2420 & 1897 & 1357 & 1547 & 7221 \\
\hline Somali & 771 & 661 & 825 & 1513 & 3770 \\
\hline Benishangul-Gumuz & 875 & 684 & 813 & 875 & 3247 \\
SNNP & 1759 & 1719 & 1274 & 1275 & 6027 \\
\hline Gambela & 647 & 511 & 670 & 704 & 2532 \\
Hareri & 614 & 509 & 547 & 583 & 2253 \\
\hline Addis Ababa & 542 & 381 & 329 & 430 & 1682 \\
Dire Dawa & 623 & 406 & 533 & 537 & 2099 \\
\hline Total & 11984 & 9737 & 9311 & 10466 & 41498 \\
\hline
\end{tabular}

*South nation nationality and people's region 

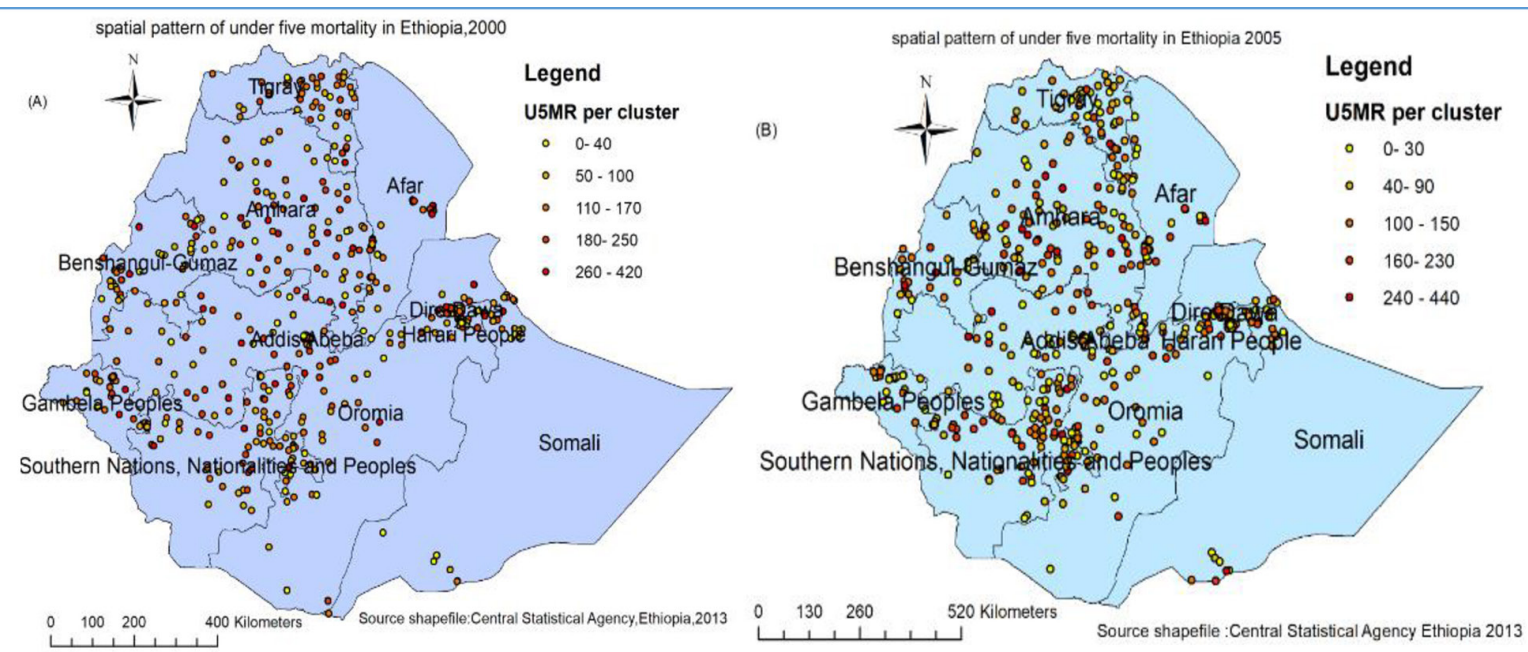

dhsprogram.com/. The EDHS sample weights were applied during analysis.

The georeferenced data were also taken from selected EAs in each survey. For the current study, the survey datasets and location data were accessed through the web page of the international DHS Programme after justifying the purpose of accessing data and after being an authorised user.

\section{Spatial analysis}

ArcGIS V.10.1 was used for spatial analysis. The spatial autocorrelation (Global Moran's I) statistic measure was used to evaluate whether the under-five mortality patterns are dispersed, clustered or randomly distributed in the study area. Moran's I is a spatial statistics used to measure spatial autocorrelation by taking the entire dataset and produce a single output value that ranges from -1 to +1 . A positive value for Moran's Index indicates a clustered pattern of the under-five mortality, while a negative value for Moran's Index indicates a dispersed pattern and under-five mortality is distributed randomly if I value is zero. $^{2324}$
Gettis-OrdGi* statistics was conducted to detect further the local level risk areas of U5MRs in Ethiopia during different periods. In this analysis, Z-score and $\mathrm{p}$ value were computed to determine the statistical significance of clustering. ${ }^{25}$ If the Z-score falls outside the range, the observed spatial pattern is probably too unusual to be the result of random chance, and the $p$ value would be small to reflect this. In this case, figuring out what might be causing a statistically significant spatial pattern in the data is considered. Statistical output with high Gi* indicates 'hotspot' (high-risk areas) of U5MR, whereas low Gi* shows a 'cold spot' (low-risk areas) of U5MR in Ethiopia. 232426

The unsampled areas of Ethiopia were also predicted by using data from sampled locations through the spatial interpolation technique. ${ }^{27}$ Of different interpolation techniques, the Ordinary Kriging spatial interpolation method was used to predict and produce smooth surfaces of U5MR risk areas.

Furthermore, to detect the local specific risk areas (clusters) of U5MR, spatial scan statistics (the method 


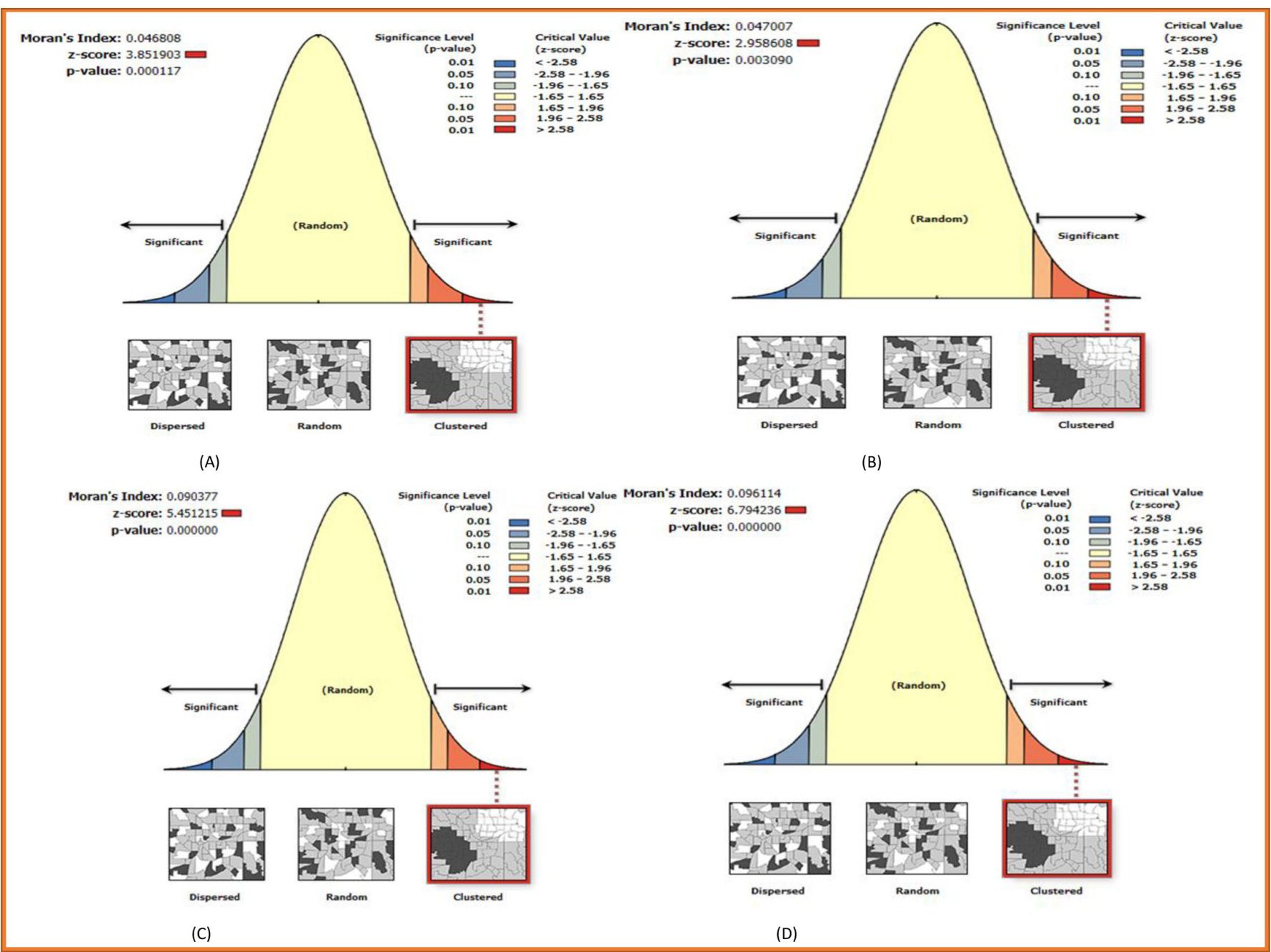

Figure 3 Spatial autocorrelation of under-five mortality in Ethiopia: 2000 (A), 2005 (B), 2011 (C) and 2016 (D).

widely recommended to detect local clusters because of its higher power than other available spatial statistical methods) was used. ${ }^{28}$ Therefore, spatial scan statistical analysis was employed to test for the presence of statistically significant spatial hotspots/clusters of U5MR using Kuldorff's saTScan V.9.6 software. ${ }^{29}$ It was used to classify statistically important under-five mortality hotspot areas. The spatial scan method uses a circular window that moves across the map and at each position; the radius of the circular window varies repeatedly from 0 up to a

Table 2 Spatial autocorrelation analysis of under-five mortality in Ethiopia: 2000, 2005, 2011 and 2016

\begin{tabular}{lllll}
\hline $\begin{array}{l}\text { EDHS study } \\
\text { year }\end{array}$ & $\begin{array}{l}\text { Observed } \\
\text { Moran's I }\end{array}$ & $\begin{array}{l}\text { Expected } \\
\text { Moran's I }\end{array}$ & Z-score & P value \\
\hline 2000 & 0.046 & -0.002 & 3.85 & $<0.01$ \\
2005 & 0.047 & -0.002 & 2.96 & $<0.01$ \\
2011 & 0.090 & -0.003 & 5.45 & $<0.01$ \\
2016 & 0.096 & -0.002 & 6.79 & $<0.01$ \\
\hline
\end{tabular}

The table shows that when the observed value is greater than the expected value and the $p$ value $<0.05$, it is statistically significant. EDHS, Ethiopian Demographic and Health Survey. set maximum radius of 50 which restricts the maximum size of the window from exceeding $50 \%$ of the total study population. In this study, under-five children who died were taken as cases, whereas those who were alive were taken as controls to fit the Bernoulli model. The numbers of cases in each location have binomial distribution and a maximum spatial cluster size of $<50 \%$ of the population was used as an upper limit.

\section{RESULT}

\section{Spatial distribution of under-five mortality}

The proportion of under-five mortality varied across regions in all surveys. The highest U5MR was observed in Benishangul-Gumuz region throughout the surveys. In 2000 survey, the highest U5MRs (260-420 deaths per 1000 live births) were observed in Benishangul-Gumuz, Afar Amhara, Tigray and Gambela regions (figure 2A). The U5MR which ranges from 240 to 440 deaths per 1000 live births occurred again in Benishangul-Gumuz, Afar, Tigray, Amhara and Oromia regions in 2005 (figure 2B). Furthermore, in 2011 and 2016, the highest 


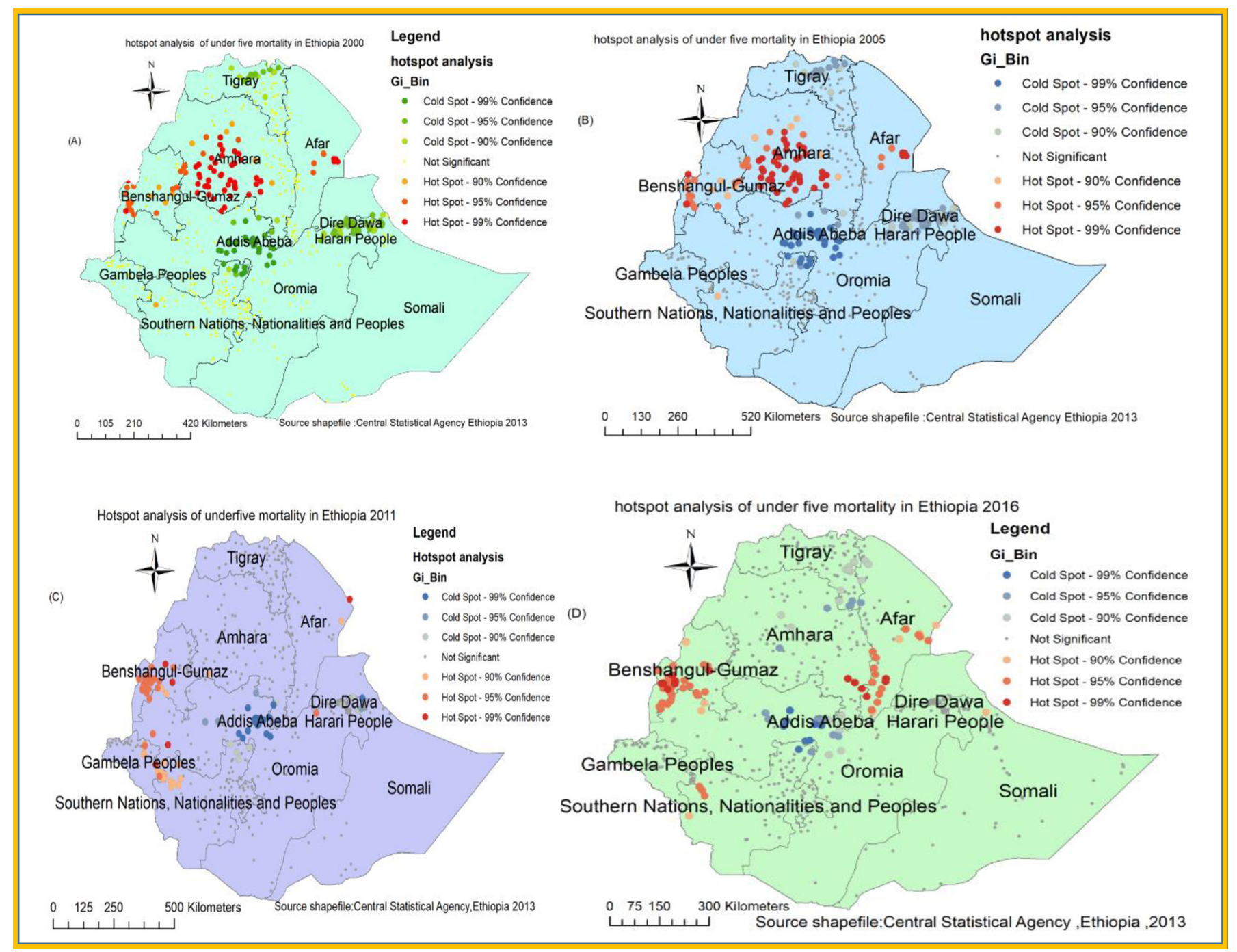

Figure 4 Hotspot analysis of under-five mortality in Ethiopia: 2000 (A), 2005 (B), 2011 (C) and 2016 (D).

U5MR occurred in Benishangul-Gumuz, Afar, southeast Amhara and SNNP Region (figure 2C,D).

\section{The spatial clustering of under-five mortality}

Results of the Global Moran's I show a statistically significant positive spatial autocorrelation of U5MRs in Ethiopia in all surveys. Based on 2000 and 2005 surveys, results showed that U5MRs had statistically significant positive spatial autocorrelation ( $\mathrm{MI}=0.05, \mathrm{p}=0.00$ and $\mathrm{MI}=0.05$, $\mathrm{p}=0.00$, respectively). The Z-score of 3.9 and 3.0, respectively, also indicated a clustered pattern (figure 3A,B, table 2). Whereas, in 2011 and 2016, the results indicate a statistically significant relatively strong spatial autocorrelation of overall U5MRs in Ethiopia ( $\mathrm{MI}=0.09$, $\mathrm{p}=0.00$ and $\mathrm{MI}=0.096, \mathrm{p}=0.00$, respectively). Besides, the Z-scores of 5.45 and 6.49 , respectively, also indicated a clustered pattern (figure 3C,D, table 2).

\section{Hotspot analysis}

Figure 4 shows the hotspot areas of under-five mortality in Ethiopia over the last two decades. The spatial clustering of under-five mortality was consistently observed at the Benishangul-Gumuz region in all surveys (figure 4).
Moreover, Amhara and Afar regions in 2000 and 2005; Afar, Gambela, SNNP and Oromia in 2011; Afar, southeast Amhara and SNNP regions in 2016 were high-risk areas of under-five mortality.

\section{Spatial scan analysis}

Overall, a total of 160 most likely (primary) clusters were detected across four surveys. Of these, 85 significant primary clusters were identified in 2000. The spatial scanning window for these clusters was located in southeast Amhara and the southern part of the Afar region. It was centred at $10.927588 \mathrm{~N}, 40.208008 \mathrm{E}$ with a radius of $224.45 \mathrm{~km}$, a relative risk (RR) of 1.36 and a $\log$-likelihood ratio (LLR) of 13.10 at $p$ value $<0.01$ (table 3 , figure $5 \mathrm{~A}$ ). It showed that the children within the spatial window had a 1.36 times higher risk of death before 5 years of age as compared with children outside the spatial window.

Whereas, in 2005, a spatial scan statistics detected a total of 67 primary clusters. The spatial window was located in the southern Amhara and eastern part of BenishangulGumuz region. It was centred at 10.754969 N, $37.924294 \mathrm{E}$ with a radius of $192.84 \mathrm{~km}$, an $\mathrm{RR}$ of 1.56 and $\mathrm{LLR}=13.93$, 
Table 3 Most likely clusters of under-five mortality in Ethiopia: 2000, 2005, 2011 and 2016

\begin{tabular}{|c|c|c|c|c|c|c|c|c|}
\hline Years & Clusters & $\begin{array}{l}\text { Enumeration areas } \\
\text { (clusters) detected }\end{array}$ & Coordinates/radius & Population & Cases & $\mathbf{R R}$ & LLR & $\begin{array}{l}P \\
\text { value }\end{array}$ \\
\hline 2000 & $1^{*}$ & $\begin{array}{l}66,68,67,73,69,70,71,72,74,159,150,82,75,151,113,123,112, \\
156,77,76,152,114,78,119,122,80,111,64,110,79,124,108,125, \\
155,60,59,58,61,115,107,120,103,127,81,118,116,109,62,57, \\
56,65,55,54,52,106,117,53,157,104,51,126,196,102,121,41, \\
105,130,63,43,247,195,212,39,194,136,42,83,214,245,40, \\
221,48,98,129,540\end{array}$ & $\begin{array}{l}10.927588 \mathrm{~N} \\
40.208008 \\
E / 224.45 \mathrm{~km}\end{array}$ & 1985 & 322 & 1.36 & 13.10 & $<0.01$ \\
\hline 2005 & $1^{*}$ & $\begin{array}{l}182,461,415,99,338,307,396,354,304,231,351,1,364,244,322, \\
479,463,511,264,447,211,97,115,212,27,17,418,149,125,15,24, \\
156,350,296,214,98,74,326,181,192,427,152,215,239,458,75, \\
270,349,110,288,187,483,218,11,22,225, \\
262,289,157,102,93,190,159,347,402,250,535\end{array}$ & $\begin{array}{l}10.754969 \mathrm{~N} \\
37.924294 \\
E / 192.84 \mathrm{~km}\end{array}$ & 1267 & 160 & 1.56 & 12.93 & $<0.01$ \\
\hline 2011 & $1^{*}$ & $100,625,276,6$ & $\begin{array}{l}10.205226 \mathrm{~N} \\
34.769722 \\
\mathrm{E} / 19.42 \mathrm{~km}\end{array}$ & 79 & 19 & 3.29 & 10.54 & 0.01 \\
\hline 2016 & $1^{*}$ & $235,585,127,362$ & $\begin{array}{l}13.750028 \mathrm{~N} \\
39.991261 \\
\mathrm{E} / 16.33 \mathrm{~km}\end{array}$ & 112 & 23 & 3.17 & 11.85 & $<0.01$ \\
\hline
\end{tabular}

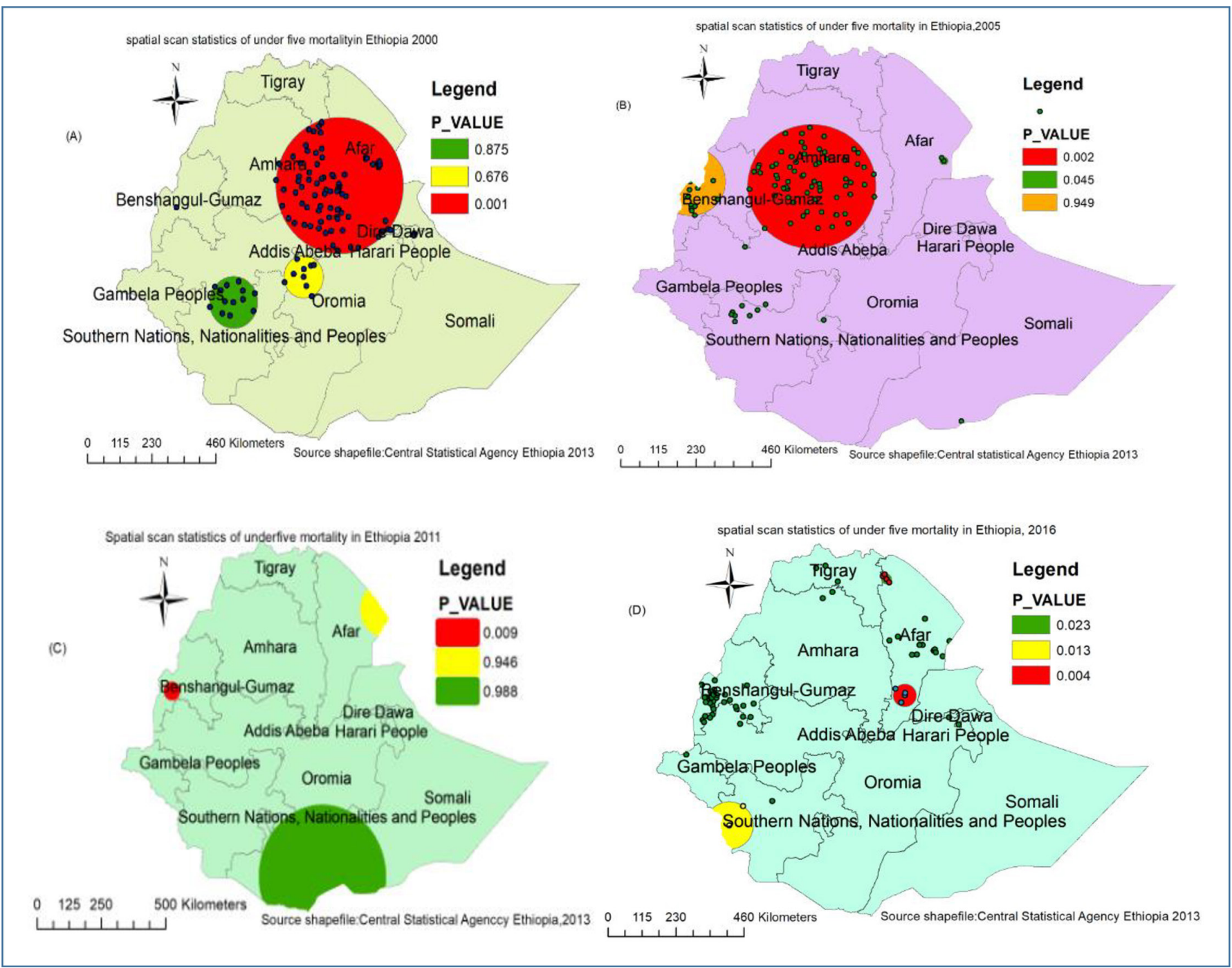

Figure 5 Spatial scan statistics of under-five mortality in Ethiopia: 2000 (A), 2005 (B), 2011 (C), 2016 (D). 
$\mathrm{p}$ value $<0.01$ (table 3 , figure $5 \mathrm{~B}$ ). The children within this spatial window had a 1.56 times higher risk of death before celebrating their fifth birthday as compared with children outside the spatial window.

Furthermore, a total of eight (four in each survey) primary clusters were identified in the 2011 and 2016 surveys. The spatial window for the 2011 survey was shifted to the Benishangul-Gumuz region which is centred at $10.205226 \mathrm{~N}, 34.769722 \mathrm{E}$ with a radius of $19.42 \mathrm{~km}$, RR of 3.29 , LLR of 10.54 at $\mathrm{p}$ value $<0.01$ (table 3 , figure $5 \mathrm{C}$ ). The risk of death before 5 years of age among the children within this spatial window was 3.29 times higher as compared with children outside the spatial window. Whereas the spatial scanning window for 2016 was detected in the southern Afar region which is centred at $13.750028 \mathrm{~N}, 39.991261 \mathrm{E}$ with a radius of $16.33 \mathrm{~km}$, the RR of 3.17 , LLR of 11.85 at $\mathrm{p}$ value $<0.01$ (table 3, figure 5D). Children within this spatial window had a 3.17 times higher risk of death before 5 years of age as compared with children outside the spatial window.

\section{Spatial interpolation}

In 2000 and 2005, the Afar (Eastern part), Tigray (north) and Oromia (west) regions were predicted as a more risky area of under-five mortality as compared with other regions (figure 6A,B). Whereas in 2011 and 2016, the risk was shifted to Afar, Gambela, Somali, SNNP and Benishangul-Gumuz regions (figure 6C,D).

\section{DISCUSSION}

Under-five mortality is a health indicator and a critical measure of human development. ${ }^{30}$ Its disparities within developing countries account for roughly half of the global gap between developed and developing countries. Thus, the evidence showed that within-country inequities deserve as much consideration as do inequalities between the world's developing and developed regions. ${ }^{31}$ Thus, the current study identified the geographic variations of risk areas of under-five mortality which could provide an insight for policy makers.

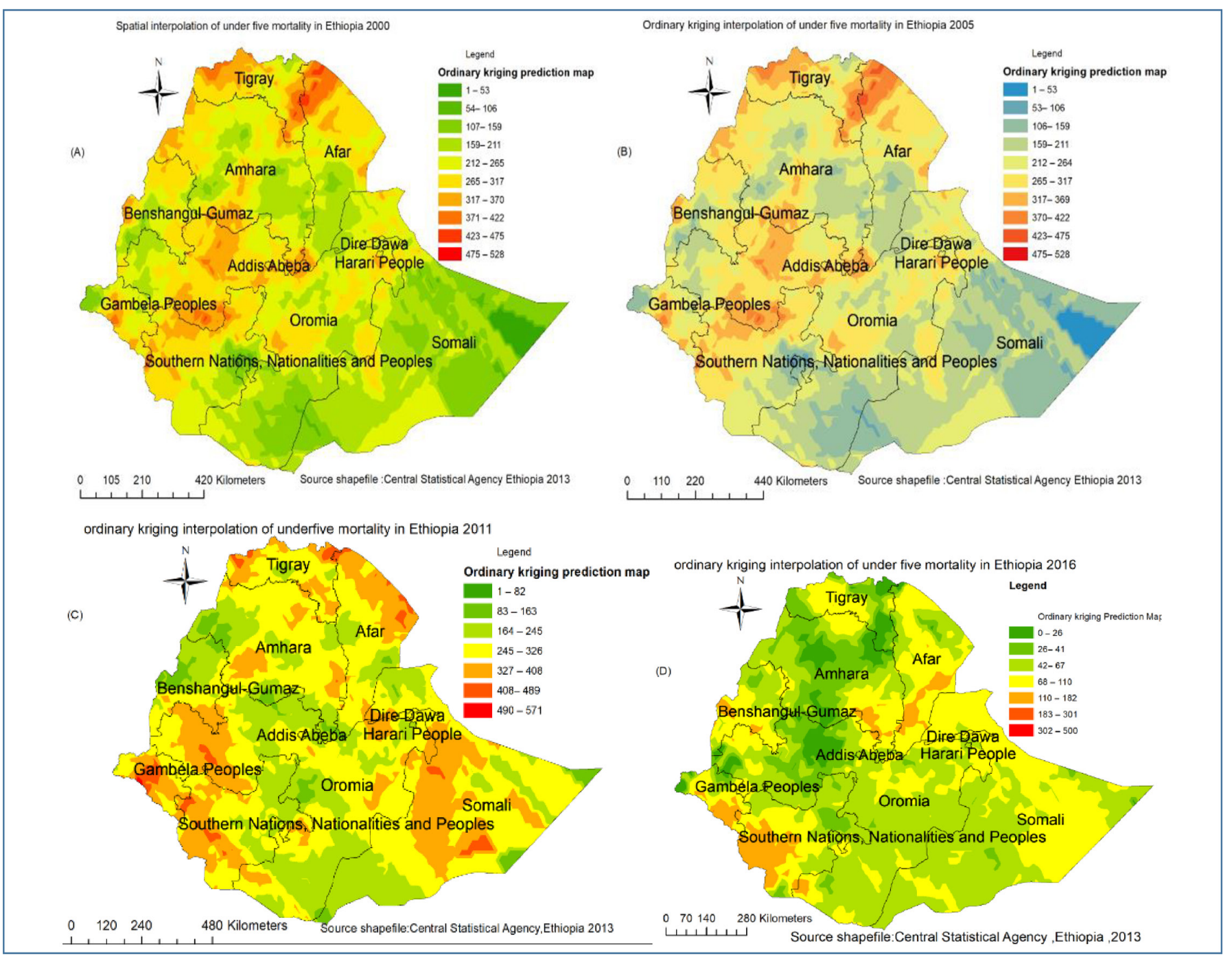

Figure 6 Spatiotemporal interpolation of under-five mortality in Ethiopia: 2000 (A), 2005 (B), 2011 (C), 2016 (D). 
The spatial autocorrelation analysis result indicated that U5MR had a spatial dependency in 2000, 2005, 2011 and 2016 (Moran's I: 0.046, 0.047; 0.09 and 0.096, respectively at $p$ value 0.01 ). This result is supported by the findings in Nigeria ${ }^{32} 33$ and Bangladesh. ${ }^{34}$ The spatial heterogeneity of under-five mortality clustering was detected mainly in Benishangul and Afar regions. These might be due to difficulty to access the health services in remote areas, shortage of safe and adequate drinking water supply, low altitude (lowland) and endemicity of malaria. ${ }^{35}$ As it was indicated in the hotspot analysis result (figure 3), the spatial clustering of under-five mortality was more or less consistently observed in the Benishangul-Gumuz region during four surveys. The possible justification could be a high multidimensional child deprivation index (MCD) where $89 \%$ of children are deprived in three to six dimensions in the Benishangul-Gumuz region. Deprivation in sanitation and housing are the largest contributors to the MCD index where Benishangul-Gumuz ranks among the most deprived regions in those two dimensions which may affect child survival. ${ }^{37}$ This might be because the majority of population in Benishangul-Gumuz region lives in the remote area. Consequently, there might be poor maternal and child health service utilisation which could lead to child deprivation in different aspects. ${ }^{38}$ Furthermore, the evidence on the determinants of child mortality in Benishangul-Gumuz indicated that the economic inequality and education is related to underfive mortality. ${ }^{39}$

Identifying the most likely clusters was very vital especially in resource-limited areas to prioritise risk areas for intervention. Hence, the spatial scan statistical analysis method performs very well in detecting local clusters and has higher power than other available methods. ${ }^{28}$ As a result, a total of 160 most likely (primary) clusters were detected across four surveys in spatial scan analysis. These clusters were primarily from Afar, Benishangul-Gumuz and Amhara regions (figure 5).

These findings have valuable policy implications for intervention and programme design. The hot spot areas of under-five mortality can be detected at local administrative levels. Generally, these findings are supremely important for the Ministry of Health and Regional Health Bearus to give attention to those hot spot areas to have good progress towards achieving sustainable development goal target for under-five mortality.

As a strength, the study used data from a nationally representative large dataset, which results in adequate statistical power. Besides, the sampling weight was applied to produce reliable estimates. However, it has the following limitations. First, the location data values were shifted 1-2 km for urban and $5 \mathrm{~km}$ for rural areas for data confidentiality issues. This may affect the exact location of cases. Second, spatial modelling was not conducted to identify the spatial determinants in those risk areas. Finally, the variation of the population in each year could introduce bias during assessment of the spatiotemporal distribution of under-five mortality.

\section{CONCLUSION}

Under-five mortality remains a public health problem and had spatial dependency over the last 20 years in Ethiopia. The hotspot (high risk) areas were detected in Benishagul-Gumuz across four surveys. Besides, Amhara, Afar, Gambela and SNNP regions were at higher risk of under-five mortality. As it was indicated by spatial scan statistics findings, most likely clusters were again detected in Afar, Amhara and Benishangul-Gumuz regions.

Therefore, public health intervention activities designed in a targeted approach to impact high-risk populations as well as geographic regions were vital to narrow the U5MR in Ethiopia.

\section{Author affiliations}

${ }^{1}$ Department of Epidemiology and Biostatistics, Institute of Public Health, College of Medicine and Health Sciences, comprehensive specialized hospital, University of Gondar, Gondar, Ethiopia

${ }^{2}$ Department of Health Education and Behavioral Sciences, Institute of Public Health, College of Medicine and Health Sciences, comprehensive specialized hospital, University of Gondar, Gondar, Ethiopia

${ }^{3}$ Department of Physiology, School of Medicine, College of Medicine and Health sciences, comprehensive specialized hospital, University of Gondar, Gondar, Ethiopia

Acknowledgements The authors would like to thank measure DHS for their permission to access the DHS datasets.

Contributors All authors contributed to data analysis, drafting or revising the article, have agreed on the journal to which the article will be submitted, gave final approval of the version to be published and agree to be accountable for all aspects of the work.

Funding The authors have not declared a specific grant for this research from any funding agency in the public, commercial or not-for-profit sectors.

Map disclaimer The depiction of boundaries on this map does not imply the expression of any opinion whatsoever on the part of BMJ (or any member of its group) concerning the legal status of any country, territory, jurisdiction or area or of its authorities. This map is provided without any warranty of any kind, either express or implied.

\section{Competing interests None declared.}

Patient and public involvement Patients and/or the public were not involved in the design, or conduct, or reporting or dissemination plans of this research.

\section{Patient consent for publication Not required.}

Ethics approval We requested DHS Programme and permission was granted to download and use the data for this study from http://www.dhsprogram.com. The Institution Review Board approved procedures for DHS public-use datasets do not in any way allow respondents, households or sample communities to be identified. There are no names of individuals or household addresses in the data files. The geographic identifiers only go down to the regional level (where regions are typically very large geographical areas encompassing several states/provinces). Each enumeration area (Primary Sampling Unit) has a PSU number in the data file, but the PSU numbers do not have any labels to indicate their names or locations. In surveys that collect GIS coordinates in the field, the coordinates are only for the enumeration area (EA) as a whole, and not for individual households, and the measured coordinates are randomly displaced within a large geographic area so that specific enumeration areas cannot be identified.

Provenance and peer review Not commissioned; externally peer reviewed.

Data availability statement Data are available in a public, open access repository. The datasets we used for this study were publicly available at http:// www.dhsprogram.com.

Open access This is an open access article distributed in accordance with the Creative Commons Attribution Non Commercial (CC BY-NC 4.0) license, which permits others to distribute, remix, adapt, build upon this work noncommercially, and license their derivative works on different terms, provided the original work is properly cited, appropriate credit is given, any changes made 
indicated, and the use is non-commercial. See: http://creativecommons.org/ licenses/by-nc/4.0/.

ORCID iD

Alemneh Mekuriaw Liyew http://orcid.org/0000-0001-9034-6205

\section{REFERENCES}

1 Wang $\mathrm{H}$, Liddell CA, Coates MM, et al. Global, regional, and national levels of neonatal, infant, and under-5 mortality during 1990-2013: a systematic analysis for the global burden of disease study 2013 . The Lancet 2014;384:957-79.

2 UNICEF. Levels and trends in child mortality: report 2019. estimates developed by the un Inter-agency group for child mortality estimation, 2015.

3 Central Statistical Agency (CSA) [Ethiopia] and ICF. Ethiopia demographic and health survey 2016. Addis Ababa, Ethiopia, and Rockville, Maryland, USA: CSA and ICF, 2016.

4 Ayele DG, Zewotir T, Mwambi H. Indirect child mortality estimation technique to identify trends of under-five mortality in Ethiopia. Afr Health Sci 2016;16:18-26.

5 Ayele DG, Zewotir TT. Childhood mortality spatial distribution in Ethiopia. J App/ Stat 2016;43:2813-28.

6 Ayele DG, Zewotir TT, Mwambi HG. Structured additive regression models with spatial correlation to estimate under-five mortality risk factors in Ethiopia. BMC Public Health 2015;15:268.

7 Organization WH. Health in 2015: from MDGs, millennium development goals to SDGs, sustainable development goals, 2015.

8 Nations U. The sustainable development goals 2016. eSocialSciences, 2016.

9 Nations U. Transforming our world: the 2030 agenda for sustainable development. General Assembley 70 session, 2015.

10 Gebretsadik S, Gabreyohannes E. Determinants of under-five mortality in high mortality regions of Ethiopia: an analysis of the 2011 Ethiopia demographic and health survey data. Int J Popul Res 2016;2016:1-7.

11 Bedada D. Determinant of under-five child mortality in Ethiopia. AJTAS 2017;6:198-204.

12 Gebre B, Ayele F. Patterns and determinants of under five mortality in Jimma town, Jimma zone, South West Ethiopia. Ethiop J Health Sci 1999;9.

13 Shamebo D, Sandström A, Muhe L, et al. The Butajira project in Ethiopia: a nested case-referent study of under-five mortality and its public health determinants. Bull World Health Organ 1993;71:389.

14 Gurmu E, Mturi AJ. Trends and determinants of Under-Five mortality in Ethiopia: could the mdg four be met? firm evidence for the increasing trend in diabetes mortality in South Africa using the data from multiple causes of death 7 Sulaiman BAH demographic time series modelling of total deaths in Nigeria 21, 2014: 49.

15 Negera A, Abelti G, Bogale T, et al. An analysis of the trends, differentials and key proximate determinants of infant and under-five mortality in Ethiopia. Calverton, Maryland USA: ICF International, 2013.

16 Bereka SG, Habtewold FG, Nebi TD. Under-five mortality of children and its determinants in Ethiopian Somali regional state, eastern Ethiopia. Health Science Journal 2017;11:1.

17 Shifa GT, Ahmed AA, Yalew AW. Socioeconomic and environmental determinants of under-five mortality in Gamo Gofa zone, southern Ethiopia: a matched case control study. BMC Int Health Hum Rights 2018;18:14.
18 Alem Berhie K, Berhie KA, Yirtaw TG. Statistical analysis on the determinants of under five mortality in Ethiopia. AJTAS 2017;6:10-21.

19 Honwana FE, Melesse SF. Socio-Economic and demographic determinants of under-five mortality in Ethiopia, 2011. Open Public Health J 2017;10:160-6.

20 Woldeamanuel BT. Socioeconomic, demographic, and environmental determinants of under- 5 mortality in Ethiopia: evidence from Ethiopian demographic and health survey, 2016. Child Dev Res 2019;2019:1-15.

21 Tobler WR. A computer movie simulating urban growth in the Detroit region. Econ Geogr 1970;46:234-40.

22 Miller HJ. Tobler's First Law and Spatial Analysis. Ann Assoc Am Geogr 2004;94:284-9.

23 Anselin L, Sridharan S, Gholston S. Using exploratory spatial data analysis to leverage social indicator databases: the discovery of interesting patterns. Soc Indic Res 2007;82:287-309.

24 Krivoruchko K. Empirical Bayesian kriging. ArcUser Fall, 2012: 6-10.

25 Zulu LC, Kalipeni E, Johannes E. Analyzing spatial clustering and the spatiotemporal nature and trends of HIV/AIDS prevalence using GIS: the case of Malawi, 1994-2010. BMC Infect Dis 2014;14:285.

26 Naish S, Tong S. Hot spot detection and spatio-temporal dynamics of dengue in Queensland, Australia. Int. Arch. Photogramm. Remote Sens. Spatial Inf. Sci. 2014;XL-8:197-204.

27 Mitas L, Mitasova H. Geographical information systems: principles, techniques, management and applications, 1999: 1.

28 Tiwari N, Adhikari CMS, Tewari A, et al. Investigation of geo-spatial hotspots for the occurrence of tuberculosis in Almora district, India, using GIS and spatial scan statistic. Int J Health Geogr 2006;5:33.

29 Kulldorff M. Software for the spatial, temporal and space-time scan statistic, 2015

30 Rajaratnam JK, Tran LN, Lopez AD, et al. Measuring underfive mortality: validation of new low-cost methods. PLoS Med 2010;7:e1000253.

31 Amouzou A, Kozuki N, Gwatkin DR. Where is the gap?: the contribution of disparities within developing countries to global inequalities in under-five mortality. BMC Public Health 2014;14:1-5.

32 Ayoade MA. Spatio-Temporal patterns of under 5 mortality in Nigeria. SSM Popul Health 2018;6:116-24.

33 Alabi O, Baloye D, Doctor $\mathrm{H}$, et al. Spatial analysis of under-five mortality clustering in northern Nigeria: findings from Nahuche health and demographic surveillance system, Zamfara state. Int $J$ Trop Dis Health 2016;15:1-10.

34 Gruebner O, Khan M, Burkart K, et al. Spatial variations and determinants of infant and under-five mortality in Bangladesh. Health Place 2017;47:156-64

35 Strasser R, Neusy A-J. Context counts: training health workers in and for rural and remote areas. Bull World Health Organ 2010;88:777-82.

36 Strasser R, Kam SM, Regalado SM. Rural health care access and policy in developing countries. Annu Rev Public Health 2016;37:395-412.

37 UNICEF. Situation analysis of children and women: BenishangulGumuz region, 2019.

38 Tiruaynet K, Muchie KF. Determinants of utilization of antenatal care services in Benishangul Gumuz region, Western Ethiopia: a study based on demographic and health survey. BMC Pregnancy Childbirth 2019;19:115.

39 Getachew KD. Determinants of Under-Five child mortality in Benishangul-Gumuz regional state of Ethiopia. Seventeenth international conference on the ethiopian economy, 2020. 